\title{
Commercial water auditing in Stella
}

\author{
S. J. Mecca ${ }^{1} \&$ S. D. Mecca ${ }^{2}$ \\ ${ }^{I}$ Department of Engineering-Physics-Systems, Providence College, \\ Providence, USA \\ ${ }^{2}$ WaterWise Technologies, Jamestown, RI, USA
}

\begin{abstract}
Stella has been successfully used to model water supply systems [1] including the representation of residential demand [2] in such systems (Stella is a product of ISEE Systems, Hanover, NH USA.) This paper documents the use of this modeling tool in simulating demand from several appliances common to commercial water users and applying this technique to commercial water auditing. The application of the model to the audits of six commercial organizations is presented. The model is being used for water management/conservation studies but also has potential for representing commercial water demand in more comprehensive supply system models.

Keywords: water audit, commercial water auditing, commercial water demand, water management, water conservation.
\end{abstract}

\section{Motivation}

The management of water resources has required extensive modelling with reliable data for both validation and decision making. Information regarding end-use consumption in residential, commercial, industrial and governmental sectors is essential in comprehensive water resource models. Yet, reliability has often meant metering, which, on a distributed basis, can be expensive and time consuming. In the residential sector, guidance on water demand can often be gleaned and scaled from large studies such as the AWWA REUW study, which spanned several areas and districts around the United States [1]. This data has been successfully scaled to a small municipal system in Jamestown, Rhode Island in the US by normalizing computed demand to billing audit data for this community [2]. The effort was motivated by a need for representing residential end-use of water in a comprehensive dynamic-stochastic water management 
model of the system [3]. A segment-representation of the model is shown in Figure 1. It had been economically unfeasible to acquire such end-use data through a distributed monitoring system in this small island community. Nevertheless, the normalized end-use data successfully represented the residential consumption in the model. The commercial sector is more challenging in that the uses of water in this sector are varied depending on the nature of the various commercial enterprises comprising the sector. For example, a commercial boating and marine operation will have a different mix of uses than will a dentist's office or a printing press or a restaurant. Nevertheless, there is a more common set of appliance-related uses, such as toilets and urinals, faucets and showers. Demand from these applications is expected to be dynamic and will depend on factors such as the number and efficiency of appliances, number of employees, patrons, etc.

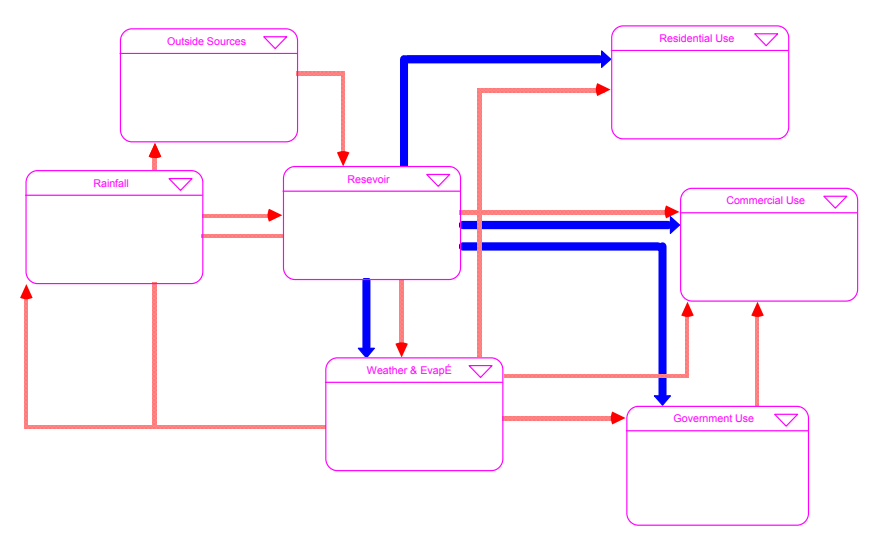

Figure 1: The major segments of a dynamic-stochastic model of a municipal water system [3].

Hence, one motivation for the present study is to address the representation of commercial end-use demand with a view towards upgrading that sector in the aforementioned dynamic-stochastic model. The impetus for one of the authors (SJM) was the (eventual) temporal and functional aggregation of water use in the commercial consumption segment of the model, a task that has been undertaken in the residential sector. See references [2] and [4] and references therein.

The motivation of the other author (SDM) was very practical. As part of an organization (WaterWise Technologies) in the business of providing water management consultation services to industrial, commercial and governmental organizations, he does extensive water auditing prior to developing a strategy of water management opportunities for clients and prospective clients. These audits have multiple dimensions and often involve reconciling billing data with calculated end-use patterns. Rather than providing long term averages, the audits are frequently expected to display dynamic patterns of water use. The effort involved in developing individual commercial audits as well as the need for 
including temporal analyses was the motivation to consider developing a dynamic commercial water audit that could be tailored to fit most if not all commercial users.

The model, depicted in segment form in Figure 1 and reported in earlier studies $[2,3]$, is written in Stella. This tool, which is widely used in system dynamics, was an appropriate choice for the present study especially since it might ultimately support the commercial demand segment of the aforementioned dynamic-stochastic municipal water resources model.
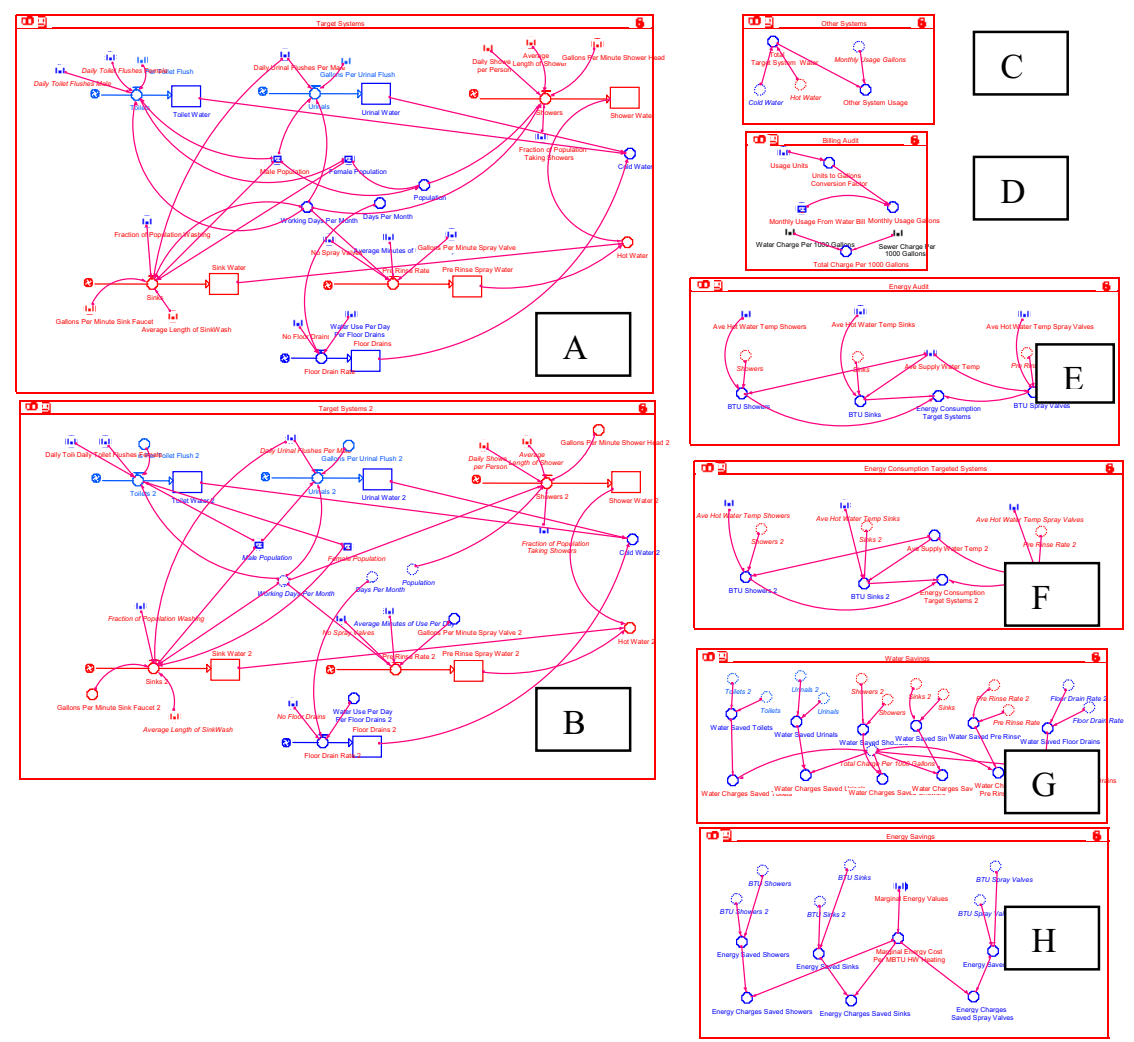

Figure 2: Overall structure of the audit model. See text.

\section{Structure of the audit model}

The commercial audit requires consideration of a common set of end-uses in this sector. It was decided to include use for six appliances somewhat universal in commercial enterprises: toilets, urinals, sink faucets, active drain-traps, showers and pre-rinse kitchen spray valves. While there are other common end-uses, these elements were chosen to reflect a mix of typical water conservation technologies. However, the model has the capacity to readily add other 
'common' end-use applications. The tool also has the ability to represent noncommon uses, i.e. applications that are more or less unique to a particular enterprise e.g. a cooling water application.

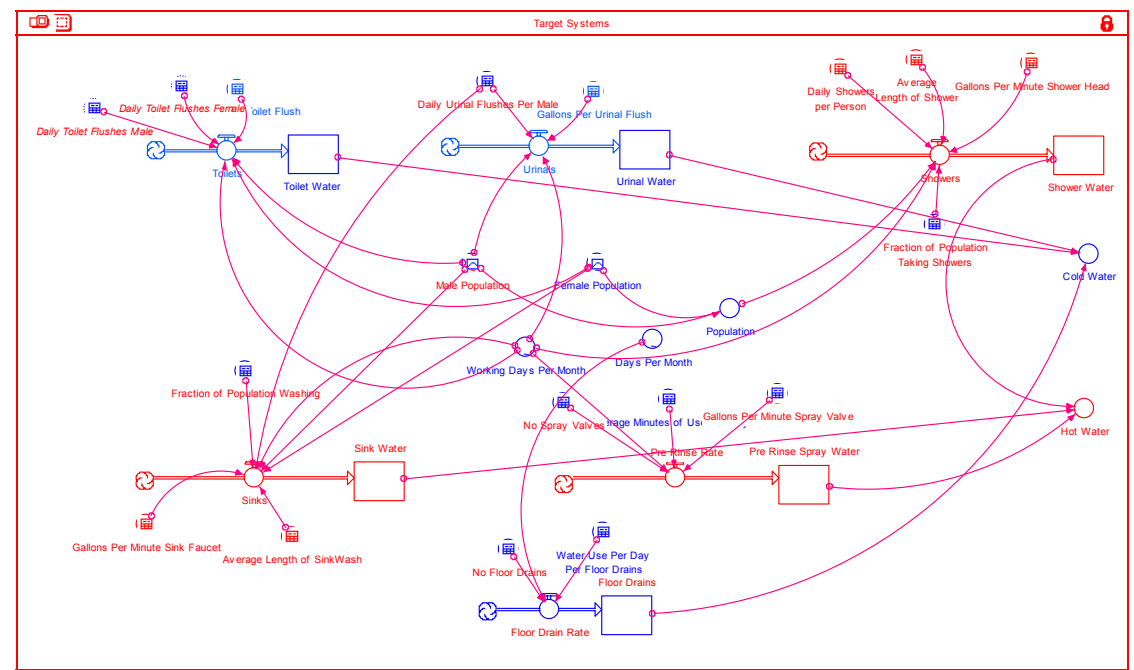

Figure 3: Graphic structure of the targeted systems segment of the model in Stella.

The audit structure is shown in Figure 2. The aforementioned common enduses are treated in segments A and B, which are labelled as 'Targeted Systems', A being used to describe the existing situation and B a proposed situation using conservation technologies, labelled as Targeted Systems P. This allows the audit to be used for exploring the potential of such technologies in targeted systems. Segment D considers water use from billing audit data and is labelled, 'Billing Audit', while section C, labelled as 'Other Systems', calculates aggregate water use from processes other than the common or targeted ones by subtracting this use from the total use found in the billing audit . (As noted earlier, this use can be disaggregated by adding custom modules for unique applications, though this is not the focus of the present paper.) Some water use, especially hot water, has corresponding energy use and this is calculated in segments $\mathrm{E}$ and $\mathrm{F}$ for Targeted Systems and Proposed Systems, Targeted Systems P. Finally, segments G and H compute water and energy savings respectively. Segments A and B have exactly the same structure and this is shown in Figure 3. The six targeted - common commercial uses are shown together with the factors affecting water use rates for these appliances. The parameters - male, female and total-population, days per month and working days per month - impact most of the six common uses. The parameters used in the model are, for the most part, self-documenting, i.e. parameter names are chosen with their commonly understood definition. These may be described functionally or graphically, the latter being the most common way. For example, the male population as a function of time of year 
can be input as a table, which is then represented as a graph in the model. These features make Stella a rather user friendly tool.

The ability to create a separate user interface makes the process even more approachable for the casual user while simultaneously isolating the user from the model layer of the audit. This interface is shown in Figure 4. The multiple pages of the interface level allow for the entry of most of the parameters in the model. Appropriate limits are set to trap user typographical errors. The full interface screen gives basic outputs of the model in both graphic and tabular form.

Commercial Water Audit Analysis - High School
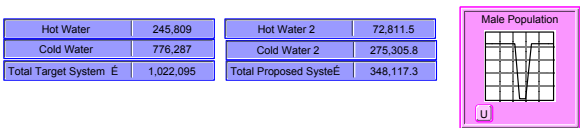

\begin{tabular}{|c|c|}
\hline Sink (Faucet) $\mathrm{W}$ & $\nabla$ \\
\hline Gallons Per Minute Sink Faucet & 1.75 \\
\hline Average Length of SinkWash & 0.25 \\
\hline Ave Hot Water Temp Sinks & 90 \\
\hline
\end{tabular}
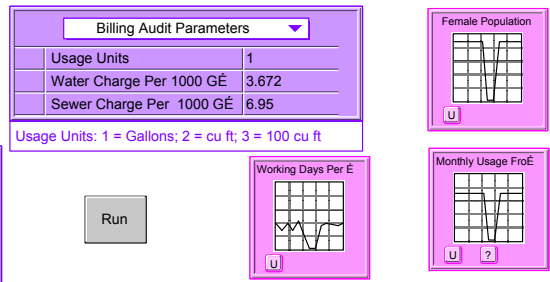

\begin{tabular}{|c|c|}
\hline Marginal Energy Inputs & $\nabla$ \\
\hline Marginal Energy Values[Oil,Percentage Used to Produce HW] & 100 \\
\hline Marginal Energy Values[Oil,Marginal Price per MBTU] & 23 \\
\hline Marginal Energy Values[Natural Gas,Percentage Used to PrÉ & 0 \\
\hline Marginal Energy Values[Natural Gas,Marginal Price per MBÉ & 0 \\
\hline Marginal Energy Values[Propane,Percentage Used to ProdÉ & 0 \\
\hline Marginal Energy Values[Propane,Marginal Price per MBTU] & 0 \\
\hline Marginal Energy Values[Coal,Percentage Used to Produce É & 0 \\
\hline Marginal Energy Values[Coal,Marginal Price per MBTU] & 0 \\
\hline Marginal Energy Values[Wood,Percentage Used to ProduceÉ & 0 \\
\hline Marginal Energy Values[Wood,Marginal Price per MBTU] & 0 \\
\hline Marginal Energy Values[Waste,Percentage Used to ProducÉ & 0 \\
\hline Marginal Energy Values[Waste,Marginal Price per MBTU] & 0 \\
\hline Marginal Energy Values[Electricity,Percentage Used to ProdÉ & 0 \\
\hline Marginal Energy Values[Electricity,Marginal Price per MBTU] & 0 \\
\hline Marginal Energy Values[Solar,Percentage Used to Produce É & 0 \\
\hline Marginal Energy Values[Solar,Marginal Price per MBTU] & 0 \\
\hline Marginal Energy Values[Other,Percentage Used to Produce $E$ & 0 \\
\hline Marginal Energy Values[Other,Marginal Price per MBTU] & 0 \\
\hline
\end{tabular}

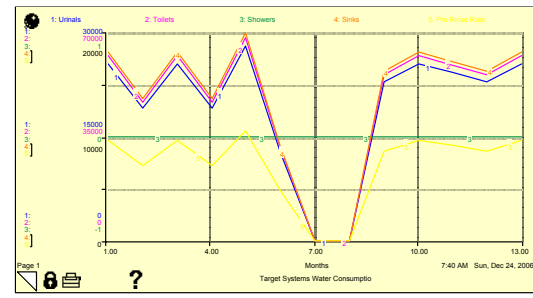

Figure 4: $\quad$ User interface for the audit model in Stella.

\section{Applications}

Six commercial enterprises were selected and water audits for common uses were carried out. The organizations and their computed consumption for common uses are summarized in Table 1.

The selected organizations focus on different functions and serve different populations. Within a few percent, total consumption, determined via a utility billing audit, was accounted for in the computed consumption for the YMCA, Audubon and Marina operations. The Marina operation, which uses much more water for its entire operation than what is shown in Table 1, had separate metering for the functions analyzed in the present study. The college dormitory was not separately metered and the high school computed consumption was $71 \%$ of its total consumption; other non-common water use functions are served there. The motel likewise used water for other purposes besides that used by clients in their rooms. The audit does not account for laundry and some staff kitchen uses. 
Table 1: $\quad$ Summary of selected organizations.

\begin{tabular}{|l|l|c|}
\hline Organization & \multicolumn{1}{|c|}{ Description } & $\begin{array}{c}\text { Computed Annual } \\
\text { Consumption for } \\
\text { Common Uses (gallons) }\end{array}$ \\
\hline YMCA & $\begin{array}{l}\text { Entire single structure athletic \& } \\
\text { administrative complex }\end{array}$ & $1,911,153$ \\
\hline Audubon & Education center & 132,058 \\
\hline College Dorm & Two-building dormitory complex & $1,083,186$ \\
\hline High School & Public secondary school & $1,022,095$ \\
\hline Marina & $\begin{array}{l}\text { Segment of a full marina } \\
\text { complex }\end{array}$ & 76,145 \\
\hline Motel & 12-unit motel complex & 316,077 \\
\hline
\end{tabular}

It is tempting to hypothesize that common-use water consumption in the commercial sector should be proportional to the average population served per day especially since the uses chosen for the common-use set in this study are appliances used by or for individuals. The scatter plot shown in Figure 5 gives the computed annual consumption as a function of average population served for the six cases included in this study.

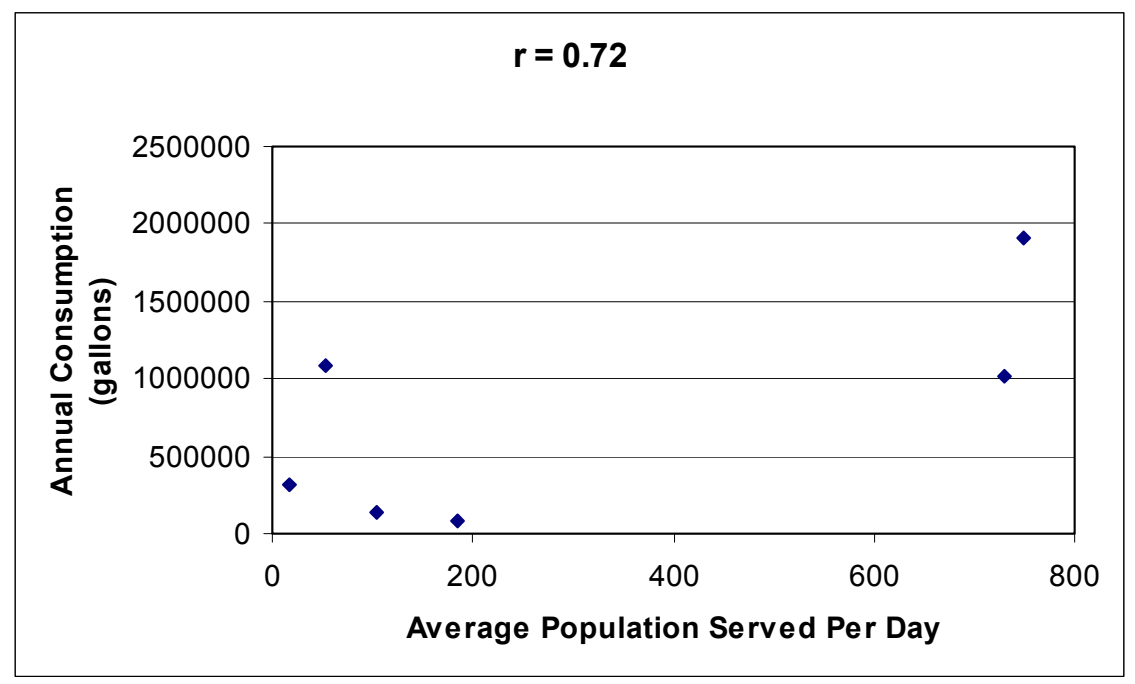

Figure 5: Computed annual consumption as a function of average population served for the six cases included in this study.

The correlation coefficient, $\mathrm{r}$, is 0.72 ; assuming unrelated variables, the probability for $r \geq 0.72$ is about $10 \%$ for this set. It is clear that reasonable estimation of commercial consumption, even consumption from appliances related to individuals, requires more than a simple over-riding parameter such as population served. Hence, the model presented herein includes parameters 
related to the appliances used, the frequencies and durations of use and differences based on gender and time. For each case, the relevant input factors were either directly measured or inferred from interview and observation. Monthly simulations were run for each case. Results for the common uses for each organization are shown in the graphs of Figure 6.
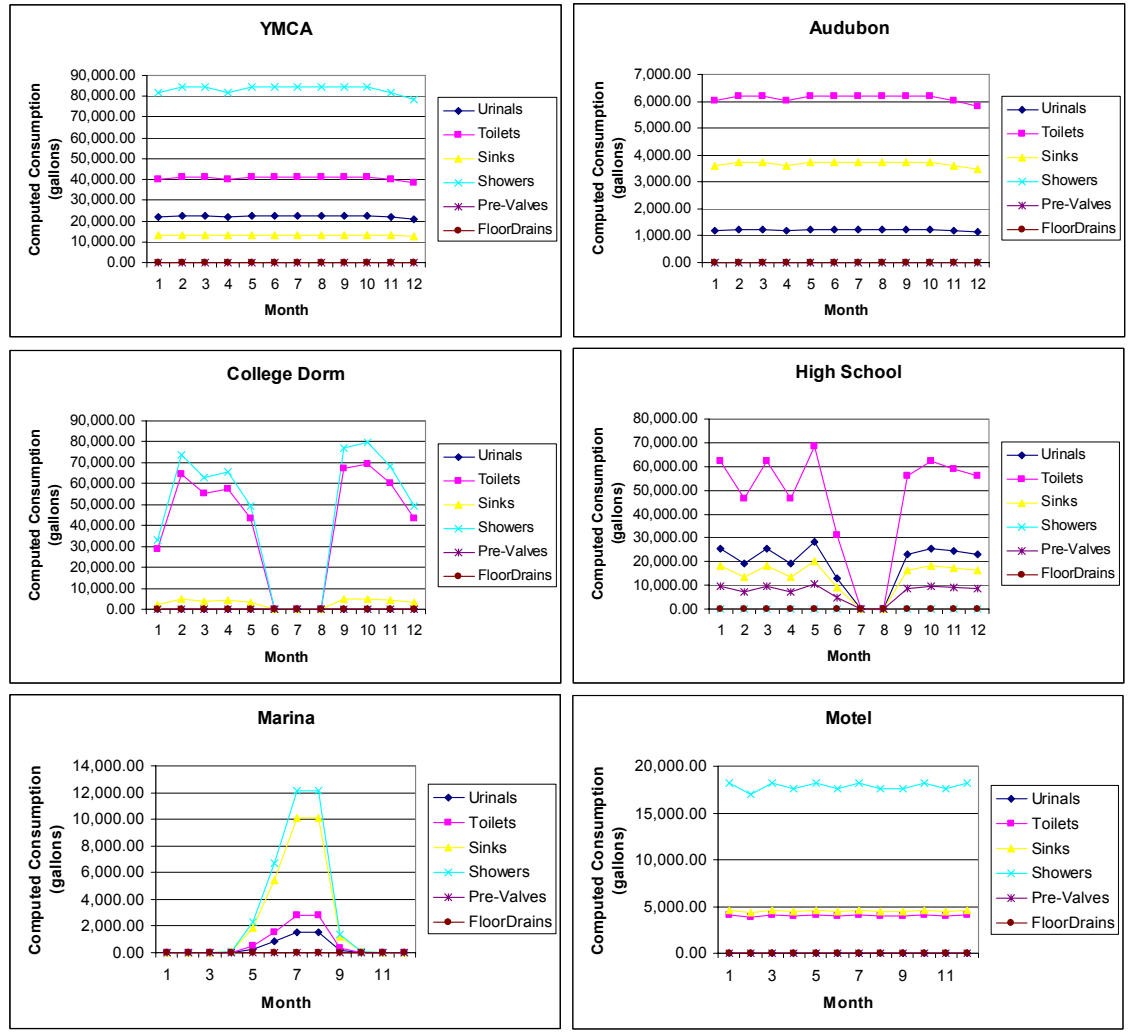

Figure 6: Computed use for targeted appliances in the 6 cases analyzed with the commercial water audit used in this study.

Several things are apparent in these results. Some operations have rather constant monthly water use; others show seasonal variations that depend on the schedule, e.g. the college dormitory and the public high school, which are generally closed during the summer months and the marina, which has its major operation during the summer months. The amount of water use for each appliance varies by enterprise both in order and relative intensity.

The audit model reported in this study is capable of computing more than present water use for targeted systems. Among the other computations and analyses are:

- Water use computed assuming implementation of available water conserving devices. 
- Estimation of 'other water uses' by subtracting computed values for common appliances from consumption determined from a billing audit.

- Estimation of energy used to produce hot water for common appliances where applicable.

- Estimation of energy to be saved from implementing the aforementioned water conserving devices.

Results for these additional computations are outside the scope of this paper. Nevertheless, it is interesting to note the projected water use for similar operations using generally available current technologies for water conservation for the six cases used in this study. These are summarized in Table 2 below.

Table 2: Computed present and projected consumption with annual water savings.

\begin{tabular}{|l|c|c|c|}
\hline Organization & $\begin{array}{c}\text { Present } \\
\text { Computed } \\
\text { Annual } \\
\text { Consumption for } \\
\text { Common Uses } \\
\text { (gallons) }\end{array}$ & $\begin{array}{c}\text { Projected Computed } \\
\text { Annual Consumption } \\
\text { for Common Uses } \\
\text { with Water } \\
\text { Conserving Devices } \\
\text { (gallons) }\end{array}$ & $\begin{array}{c}\text { Savings (gallons) } \\
\text { Percentage savings } \\
(\%)\end{array}$ \\
\hline YMCA & $1,911,153$ & 800,925 & $1,110,228(58 \%)$ \\
\hline Audubon & 132,058 & 44,028 & $88,030(67 \%)$ \\
\hline $\begin{array}{l}\text { College } \\
\text { Dormitory }\end{array}$ & $1,083,186$ & 358,566 & $724,620(67 \%)$ \\
\hline High School & $1,022,095$ & 348,117 & $673,978(66 \%)$ \\
\hline Marina & 76,145 & 22,251 & $53,894(71 \%)$ \\
\hline Motel & 316,077 & 117,717 & $198,360(63 \%)$ \\
\hline
\end{tabular}

The savings projected in Table 2 are significant as is the investment potential. Simple paybacks for both water and energy in order from shortest to longest are as follows: YMCA - 17 months, Motel - 26 months, High School - 35 months, Marina - 40 months, and Audubon - 76 months. The College Dormitory Complex had two buildings one of which had a 12 month simple payback and the other a 40 month payback on investment. Payback periods generally depend on the user to fixture ratio (for toilets and urinals) and the pattern of showerhead use; the dorm with the low payback period had an average user to fixture ratio much higher than the one with the longer payback time. In addition, much of its water use came from showerheads which have the benefits of low replacement cost and significant energy savings. The energy savings impact on the total conservation opportunity is a factor that is well documented by deMonsabert and Liner [5].

\section{Conclusions}

A dynamic model written in Stella and used to compute water use from six common appliances has been developed and applied to six commercial 
enterprises. The model was originally motivated by a need to augment the commercial water demand sector of a previously reported municipal water system model [3] and by a separate need to represent water use to commercial clients who are considering several generally available water management strategies in connection with their operations. For the six cases studied, there is sufficient variability of demand in both time and relative intensity even for common-appliance uses to suggest the value of a dynamic model that disaggregates such uses enterprise by enterprise. While further analyses are required before the present audit can be used in a summative approach to representing overall commercial demand in the aforementioned municipal water system model, it has provided some insights into that problem. It has met the second need for representing water consumption and water management strategies for individual commercial water users.

\section{Acknowledgements}

One of the authors (SJM) wishes to thank MaryTeresa Monaghan-Pendergast and Jeffrey Gandt, students in the Department of Engineering-Physics-Systems at Providence College for carrying out preliminary efforts at the early stages of this work.

\section{References}

[1] Mayer, P.W., DeOreo, W.B., Opitz, E.M., Klefer, J.C., Dziegielewski, B., Davis, W.Y., Nelson, J.O., Residential End Uses of Water, v-xxxvii, 1999 American Water Works Association Research Foundation.

[2] Mecca, S.J. \& Dotto, S. Normalizing residential water demand to water consumption, Water Resources Management III, edited by M. De Conceicao Cunha, University of Coimbra, Portugal and C.A. Brebbia, Ecology and the Environment Vol. 80, UK, 2005.

[3] Mecca, S.J. \& LaMontagne, R. Dynamic-Stochastic Modeling of a Municipal Water Supply System in Stella, Water Resources Management II, edited by C.A. Brebbia, Progress in Water Resources Vol. 8, UK, 2003.

[4] Guercio, R., Magini, R. \& Pallavicini, I., Temporal and spatial aggregation in modeling residential water demand, Water Resources Management II, edited by C.A. Brebbia, Progress in Water Resources Vol. 8, UK, 200.

[5] S. deMonsabert and B. Liner, Watergy: A water and energy conservation model for federal facilities, CONSERV'96, Orlando, Florida, January 6, 1996. http://www1.eere.energy.gov/femp/pdfs/watergy_manual.pdf 